\title{
Soft Switched Bi-directional Power Converter for Photo Voltaic System
}

\author{
L. Sahaya Senthamil ${ }^{1}$, R.Sivapriyan ${ }^{2}$, C.V. Mohan ${ }^{3}$, P. Sundaramoorthi ${ }^{4}$ \\ \{elsahayam@gmail.com¹, sivapriyan@gmail.com², mohan_eee@sirmvit.edu ${ }^{3}$, \\ sundarped.sundar66@gmail.com ${ }^{4}$ \}

\begin{abstract}
${ }^{1}$ Professor, Department of Electrical and Electronics Engineering, PSNA College of Engineering and technology, Dindigul, India, ${ }^{2}$ Associate Professor, Department of Electrical and Electronics Engineering, Sir MVIT, Bangalore, India, ${ }^{3}$ Associate Professor, Department of Electrical and and Electronics Engineering, Nehru College of Engineering and Research Centre, Thrissur, India
\end{abstract} \\ Electronics Engineering, Sir MVIT, Bangalore, India, ${ }^{4}$ Associate Professor, Department of Electrical
}

\begin{abstract}
This work proposes the implementation of a bidirectional current-fed soft switched converter for solar photo voltaic system is examined and covered with information. Effective function of the bi-directional buck-boost topology is guaranteed by continuous-duty buck-boost circuit under large voltage spectrum. In battery charger mode, phase shift modulation and pulse width modulation control are employed. In order to allow the MOSFETs to have zero voltage switching, a feedforward loop was applied to the charging mode of the battery. Compared with the conventional bidirectional soft switched converter, this one would definitely be better suitable for designing such magnetic components. This bi directional converter is implemented for a solar structure and experiment results are obtained.
\end{abstract}

Keywords: Bi Directional Converter, Solar Photo Voltaic, Soft Switching, Maximum Power Point Tracking.

\section{Introduction}

The application of solar photovoltaic is a modern concept and therefore must be applied by different method and technique. Electronic controls are used for the operation of thermal power plants. It is important to contain high performance transformer. Boost converters have lots of uses in high current, heavy loads settings. Solar photovoltaic power generation module is a strong choice for high voltage bus systems since it transforms sunlight into electricity. Since Converters that are actually feeding current are more powerful than conventional Converters that are actually feeding voltage, they have less limitations. Present limiting feature is important when interacting with very broad currents. This is that the former has more flaws than the latter. Transformer parasitic are very efficient in addressing Switching issues. and heavy switching losses of LCC. The earliest mechanical coupling between trains is a soft switched converter. There are different forms of soft switched series and parallel converters. This new breakthrough can be implemented by the researchers in many forms. The major categories of LC resonating converters are LCF-type, LC-type, LLC-type, LCC-type, CLLC-type, etc. The frequency varies to balance the rate of usage. 


\section{Solar Photovoltaic System}

The proposed topology for solar PV scheme can be seen in Figure 1. The most critical aspects of the device are solar panel and MPPT/ Bi directional loop.

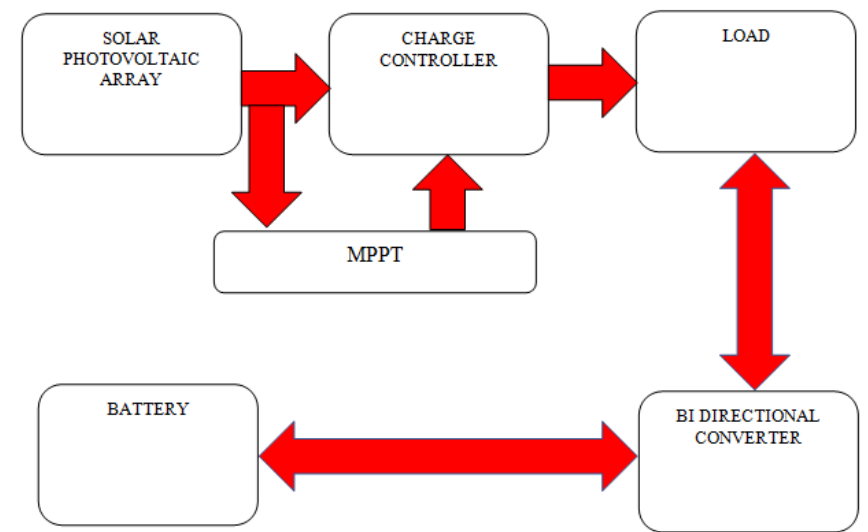

Fig. 1. Block diagram of proposed system with bi directional converter

\section{Modelling of Solar PV Module}

The sun's power density at $50 \mathrm{~km}$ altitude is roughly 1,373 kilowatts per square metre. part of the electricity provided to the world by the Planet is emitted into the environment by radiation. The solar lighting decreases to I kW/m2 at the surface of Earth at noon in the tropics. Solar panels turn sunlight into electricity. A photovoltaic device is the fundamental feature of a solar cell. Solar cells will take sunlight's energy directly and turn it into electrical electricity. Solar power is technologically used to transform sunlight into electrical energy. Solar photovoltaic cells (PV) generate electricity. Electricity may be used to power anything such as tv, microwave, drinking water pumping, illumination etc. A simpler alternative circuit of a solar cell is seen in figure 2. A solar cell generator is paired with a variable resistor. Current is flowing through the diode when the contacts are connected. The light hitting at the cathode induces photocurrent (Iph). The largest existing threshold for solar cell is $1 /$ second. If the diode junction voltage rises, a percentage of the output current passes into the diode, where the voltage falls by the equal number. Output voltage is zero when load resistor is not attached. From Diode Parameter Equation, at RDS $=0$ relationships can be determined.

Currently, one photovoltaic cell produces a photovoltaic dc in the form of a shifting dc. For converters to operate properly, each panel must be attached in parallel. Solar installation consisting of more than one solar cell and one solar cell module. The equations governing solar cell are 


$$
\begin{aligned}
& I_{D}=I_{0}\left(e^{\frac{V_{P V}}{\propto V_{T}}}-1\right) \\
& I_{P V}=I_{S C}-I_{0}\left(e^{\frac{q\left(V_{P V}+I_{P V} \cdot R_{S}\right)}{\propto K T}}-1\right)-\frac{V_{P V}+I_{P V} \cdot R_{S}}{R_{S h}} \\
& V_{P V}=\propto V_{T} \ln \left[\frac{\left(I_{S C}-I_{P V}\right)}{I_{0}}+1\right]
\end{aligned}
$$

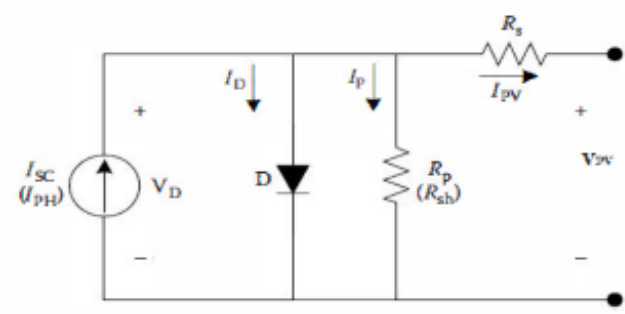

Fig. 2. Solar photovoltaic cell equivalent circuit

$$
\begin{aligned}
& \text { Where, } \\
& \mathrm{I}_{\mathrm{D}}=\text { Current flowing through the diode } \\
& \mathrm{T}=\text { photovoltaic cell temperature } \\
& \mathrm{I}_{0}=\text { reverse bias current under saturation } \\
& \mathrm{V}_{\mathrm{PV}}=\text { voltage of the solar panel } \\
& \mathrm{K}=\text { Boltzmann's constant }=1.380 \times 10^{23} \\
& \mathrm{~V}_{\mathrm{T}}=\text { voltage at a particular temperature } \\
& \mathrm{I}_{\mathrm{PV}}=\text { panel current } \\
& \mathrm{Q}=\text { charge of electron } \\
& \mathrm{V}_{\mathrm{T}}=\mathrm{KT} / \mathrm{q} \\
& \mathrm{I}_{\mathrm{SC}}=\text { current of the photon } \\
& \alpha=\text { factor of ideality }
\end{aligned}
$$

When it comes to the production of current and voltage from solar electricity, the output depends on the temperature and irradiance. The solar PV module is designed to work at a specific performance under ideal conditions. The full power drawn from the PV cell is critical to enhancing the efficacy of the solar cell. Several studies have been performed on MPPT methods for estimating maximum solar panel power. The voltage technique under open circuit is the most affordable one and economic ways to be applied. Therefore, the open circuit voltage system shall be used in execution.

\subsection{Constant Voltage MPPT Algorithm}

The ultimate aim may be realized by controlling current or voltage or both. The fastest and cheapest way of applying the LED lighting is with the constant voltage method. Figure 3 represents the MPPT voltage algorithm.

$\mathrm{Vpv}$ and Vmp have a direct bond that gives $\mathrm{Vpv}=\mathrm{kVmp}$ Anywhere Vmp is the maximum power point voltage. The $\mathrm{k}$ factor has a range of 0.71 to 0.78 , which helps one to use the above formulas to calculate the VMPP and set it as a guide. The panel is measured by calculating the 
immediate voltage input from the solar panel and then matching it with the locus voltage. Next, the discrepancy between the two is used to evaluate whether there is some defect.

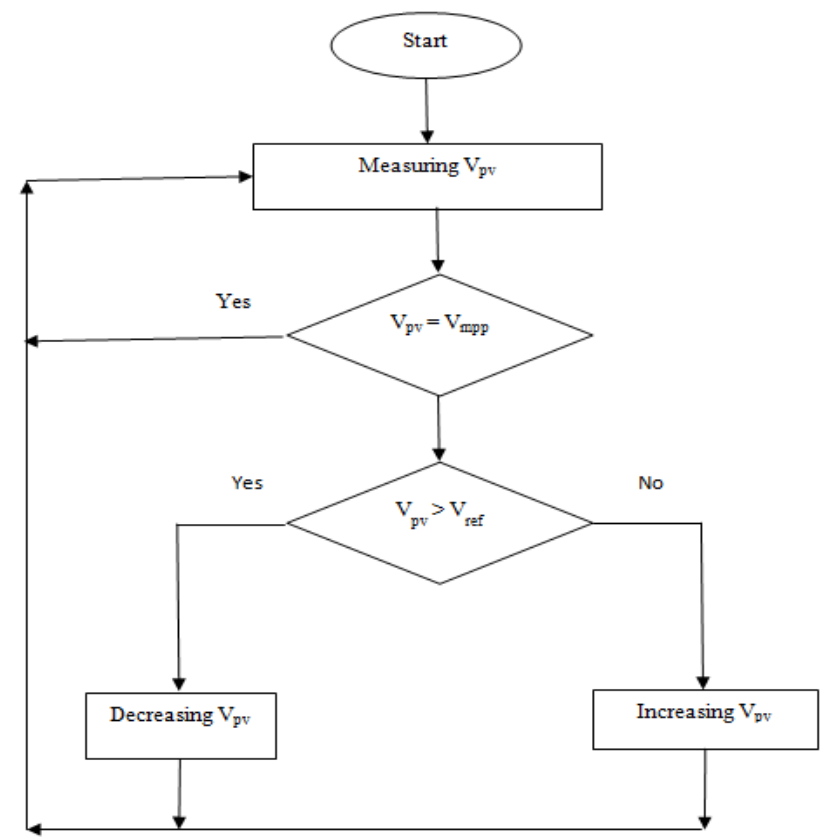

Fig. 3. Constant Voltage MPPT Algorithm

\subsection{Bi-directional DC- DC converter}

The CFBRC comprises a series attached buck boost converter and a soft switched converter circuit for discharging battery. In action, the soft switched converter with LLC tank converts into a soft switched converter when attached to a constant voltage source, as seen in Fig. 1. The pairs of switches S1, S2 and S3, S4 form two complete full-bridge circuits. The two buckboost circuits are composed by linking Lb1 and Lb2 to the ends of the legs of the bridge. As with interleaved systems, the two boost-buck converters operate $180^{\circ}$ out of phase. Meanwhile, a full-bridge transformer consisting of a soft switched inductor, a soft switched capacitor, and a magnetizing inductor is formed by utilizing a series inductor, a series capacitor and a series magnetizing inductance. The auxiliary-capacitor is charged from the battery and is the voltage that powers the engine. Same Voltage over the bus. In the figure, duty period D is operated by Service S1 and complementary Service S4 .

$\mathrm{S} 1$ and S3 have the same job period, but are based off each other $180^{\circ}$. Voltage of the battery would still stay the same. Besides, at this period the secondary side changes, S5 S8 are synchronously rectified and the oscillation frequency of the open-circuit voltage is changed. $\varphi 1$ is having the angular phase-shift for charging battery in this mode. The angular phase change between S5 and S8 lies between S5 and S1Through using feed-forward method to handle the latest ZVS converter can be run in a typical context. In comparison, the capacitor voltage and battery voltage are both the same. 


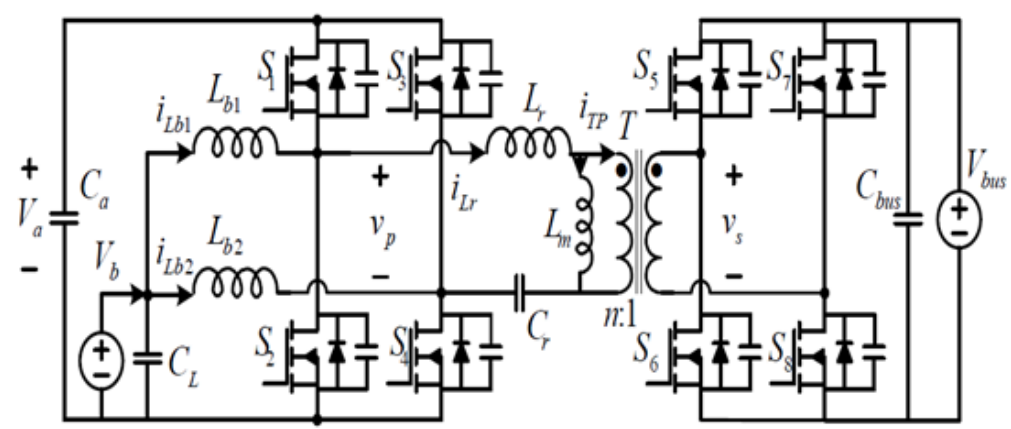

Fig. 3. Bi-directional Converter Circuit

This can be monitored to manage $\varphi 1$ and task cycle D. In order to determine the operational conditions of the mode of charge and discharge, it is reasonable to conclude that $\mathrm{D}<0.5$.

\subsection{Preventive and monitoring technique.}

Control technique such as the battery charging and discharge mode of the CFBRC is applied in this section. PWM power and switching frequency is equivalent to the soft switched frequency $\mathrm{f}$. Charge current is regulated to maintain DC voltage bus stable as the battery voltage varies. The sinusoidal wave is an indicator of the reciprocating current. In this way, the CFBRC can function optimally over the diverse input voltage range. We use phase shift power in the charging mode of the battery. To reduce switch frequency, the step between S5 and S8 is established as a persistent rate to ensure the soft switching of the lagging switches at the same time. Regulation of the battery voltage is utilizing step $\varphi 1$ between C5 and A1.

\section{Experimental Results}

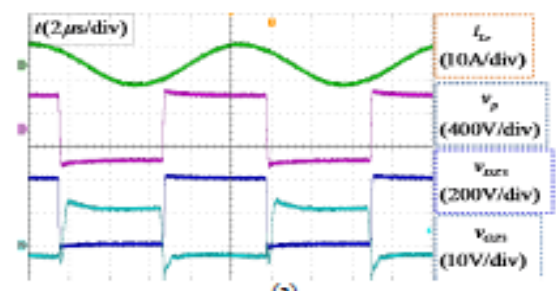

(a)

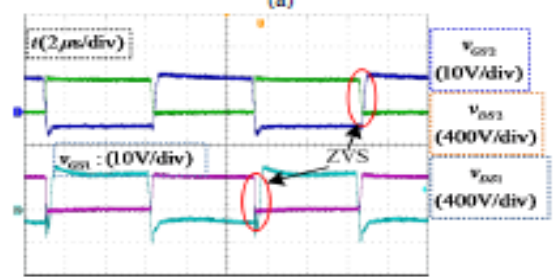

Fig. 5. Waveforms in discharging mode with $\mathrm{Vb}=200 \mathrm{~V}$

To prepare for this experiment, a 1500-W micro-grid prototype was constructed with range of battery voltage from $150 \mathrm{~V}$ to $240 \mathrm{~V}, 400 \mathrm{~V}$ voltage bus and capacitor voltage rated $400 \mathrm{~V}$. 
During battery discharging, the frequency decreases from $85 \mathrm{kHz}$ to $95 \mathrm{kHz}$, and in battery charging, it goes from $125 \mathrm{kHz}$ to $145 \mathrm{kHz}$. The voltage rule for a battery is represented in Figure 5 and figure 6.

This indicates that when the lights were switched on, the drain-to-source voltage had already gone down. ZVS can be mutually realized by all the participants of the discussion. Currently, the flipping frequency spectrum is between $85 \mathrm{kHz}$ and $95 \mathrm{kHz}$ and the soft switched frequency has maximum functionality. Figure Image. This graph reflects the hypothetical effects of charging at a voltage of $200 \mathrm{~V}$. The two voltages at the monitor will be ZVS. Within the range from $125 \mathrm{kHz} \sim 145 \mathrm{kHz}$, the switch frequency band significantly decreases the electrical signal distortion.

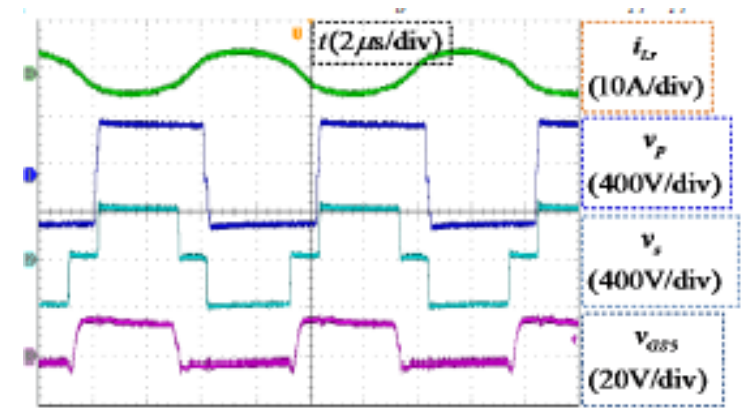

(a)

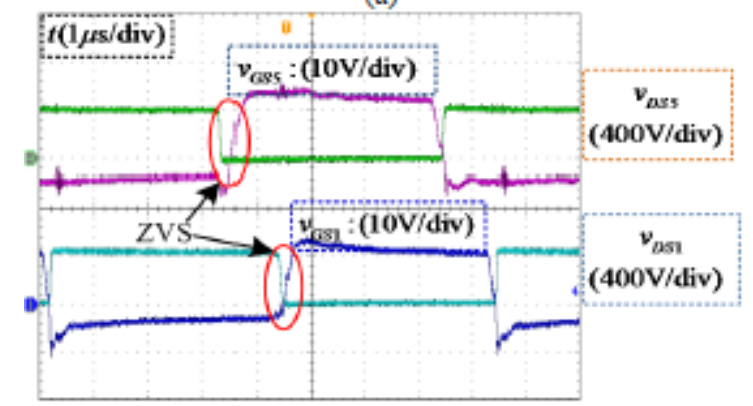

Fig. 6. Waveforms in charging mode with $\mathrm{Vb}=200 \mathrm{~V}$

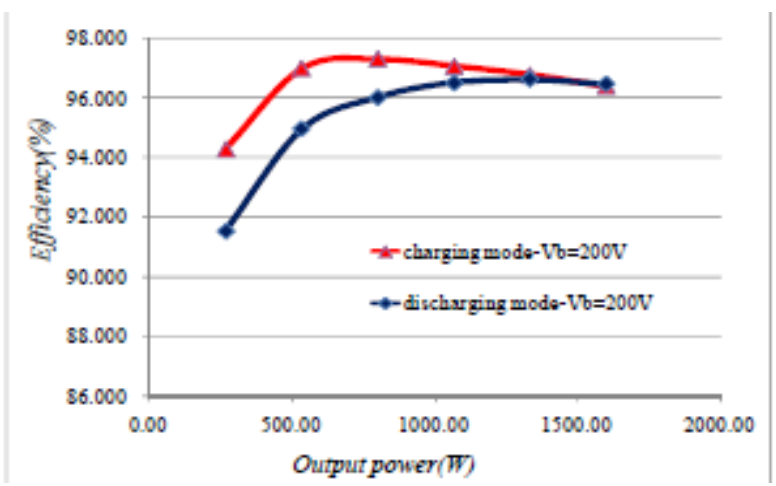

Fig. 7. Battery discharge/charge performance tested 
The downside of the SRC's broad frequency spectrum variation. Experimental results help the theoretical study. Figure 7 shows the battery performance under tested condition. These graphs show that at $11 \mathrm{~V}$, the battery is working dramatically. The converters in the entire load range will function reliably

\section{Conclusion}

The projected current fed soft switched bi directional converter performance is experimented and evaluated. This converter has reduced switching frequency, soft switching for all switches, minimum switching loss and wide range of gain related to other soft switched converters. The soft switched tank circuit of the converter acts as an integrated part of transformer causing reduction in power circulating in the converter and excellent efficiency. Thus, this passive bi directional converter is much suitable for solar photo voltaic application.

\section{References}

[1] S. B. Kjaer, J. K. Pedersen and F. Blaabjerg, "Power inverter topologies for photovoltaic modules-A review", Proc. 37th IEEE-IAS Annu. Meeting, vol. 2, pp. 782-788, 2002-Oct.-13-18.

[2] Juan Manuel Carrasco, Leopoldo Garcia Franquelo, Jan T. Bialasiewicz, Eduardo Galván, Ramón C. Portillo Guisado, Ma. Ángeles Martín Prats, José Ignacio León, and Narciso Moreno-Alfonso, "Power-Electronic Systems for the Grid Integration of Renewable Energy Sources: A Survey", IEEE Transactions on Industrial Electronics, Vol. 53, no. 4, August 2006.

[3] M. Jamil, B. Hussain, M. Abu-sara, R. Boltryk and S. Sharkh, "Microgrid Power Electronic Converters: State of Art and Future Challenges", 2009 Proceedings of the 44th International, pp. 15, Sept. 2009.

[4] G-J Su, D. J. Adams, F. Z. Peng, and H. Li, "Experimental evaluation of a soft-switching DC/DC converter for fuel cell vehicle applications" IEEE Power Electronics in Transportation, 2002, pp. 39-44.

[5] Shigenori Inoue, Hirofumi Akagi, "A Bi-Directional DC/DC Converter for an Energy Storage System," in Proc. IEEE APEC, 2007, pp. 761-767.

[6] A. Kirubakaran, S. Jain and R. K. Nema, "A review on fuel cell technologies and power electronic interface", Elsevier Renewable and Sustainable Energy Reviews, vol. 13, no. 9, pp. 2430-2440, 2009.

[7] R. Y. Chen, R. L. Lin, T. I. Liang, I. F. Chen and K. C. Tseng, "Current-fed full-bridge boost converter with zero current switching for high voltage applications", Conf. Rec. IAS Annu. Meeting, vol. 3, pp. 2000-2006, 2005.

[8] V. Vaisanen, T. Riipinen, J. Hiltunen and P. Silventoinen, "Design of $10 \mathrm{~kW}$ soft switched pushpull DC-DC converter for solid oxide fuel cell applications," in Proceedings of the 2011-14th European Conference on Power Electronics and Applications (EPE 2011), 2011.

[9] G. Ma, W. Qu, G. Yu, Y. Liu, N. Liang and W. Li, "A zero-voltage-switching bidirectional dc-dc converter with state analysis and soft-switching-oriented design consideration", IEEE Trans. Ind. Electron., vol. 56, no. 6, pp. 2174-2184, Jun. 2009.

[10] Y.-C. Chuang, Y.-L. Ke and S.- Y. Chang, "Highly-efficient battery chargers with parallel-loaded soft switched converters", Industry Applications Society Annual Meeting 2009. IAS 2009. IEEE, pp. $1-10$, Oct 2009. 
[11] S. Samanta and A. K. Rathore, "Analysis and design of current-fed (L)(C) (LC) converter for inductive wireless power transfer (IWPT)", Proc. IEEE Energy Convers. Congr. Expo. (ECCE), 2015.

[12] F. Musavi, M. Craciun, D. S. Gautam, W. Eberle and W. G. Dunford, " An LLC soft switched DCDC converter for wide output voltage range battery charging applications ", IEEE Trans. Power Electron., vol. 28, no. 12, pp. 5437-5445, Dec. 2013.

[13] M.K. Kazimierczuk and D. Czarkowski, "Soft switched Power Converters", Power, vol. 7, pp. 632, June 2012

[14] T. Zhao, G. Wang, S. Bhattacharya and A. Q. Huang, "Voltage and power balance control for a cascaded H-bridge converter-based solid-state transformer", IEEE Trans. Power Electron, vol. 28 , no. 4, pp. 1523-1532, Apr. 2013.

[15] S. Inoue, and H. Akagi, "A Bi-Directional dc/dc converter for an energy storage system," Twenty Second Annual IEEE Applied Power Electronics Conference, 2007. 